\title{
A POLYMERASE-CHAIN-REACTION ASSAY FOR THE SPECIFIC IDENTIFICATION OF TRANSCRIPTS ENCODED BY INDIVIDUAL CARCINOEMBRYONIC ANTIGEN (CEA)-GENE-FAMILY MEMBERS
}

\author{
J. ThOMPSON ${ }^{1,4}$, S. MÖSSINGER ${ }^{1}$, V. REICHARDT ${ }^{1}$, U. ENGELS ${ }^{1}$, N. BEAUCHEMIN ${ }^{3}$, F. KOMMOSS ${ }^{2}$, S. VON KLEIST $^{1}$ \\ and W. ZIMMERMANN ${ }^{1}$ \\ ${ }^{1}$ Institute of Immunobiology and ${ }^{2}$ Department of Gynecology, Freiburg University, Germany; and ${ }^{3}$ McGill Cancer Center, \\ McGill University, Montreal, Canada.
}

\begin{abstract}
Carcinoembryonic antigen (CEA) is a tumor marker that belongs to a family of closely related molecules with variable expression patterns. We have developed sets of oligonucleotide primers for the specific amplification of transcripts from individual CEA-family members using the reverse transcriptase/ polymerase chain reaction (RT/PCR). Specific primer sets were designed for CEA, non-specific cross-reacting antigen (NCA), biliary glycoprotein (BGP), carcinoembryonic antigen genefamily members 1, 6 and 7 (CGMI, CGM6 and CGM7), and one set for all pregnancy-specific glycoprotein (PSG) transcripts. Primers were first tested for their specificity against individual cDNA clones and product-hybridization with internal, transcriptspecific oligonucleotides. Total RNA from 12 brain and 63 gynecological tumors were then tested for expression of CEArelated transcripts. None were found in tumors located in the brain, including various mesenchymal and neuro-epithelial tumors. CEA and NCA transcripts were, however, present in an adenocarcinoma located in the nasal sinuses. In ovarian mucinous adenocarcinomas, we always found co-expression of CEA and NCA transcripts, and occasionally BGP MRNA. CEArelated transcripts were also found in some serous, endometrioid and clear-cell ovarian carcinomas. CEA, NCA and BGP transcripts were present in endometrial carcinomas of the uterus and cervical carcinomas, whereas uterine leiomyomas were completely negative. No transcripts were found from CGMI, CGM6, CGM7 or from PSG genes in any of the tumors tested. The PCR data were compared with immunohistochemical investigations of ovarian tumors at the protein level using CEA (26/3/13)-, NCA-50/90 (9A6FR) and NCA-95 (80H3)specific monoclonal antibodies.

(c) 1993 Wiley-Liss, Inc.
\end{abstract}

Tumor markers are usually defined as molecules produced by malignancies, whose presence or altered serum concentration, as compared with normal values, gives an indication that a tumor exists. Carcinoembryonic antigen (CEA) is a widely used human tumor marker for a variety of carcinomas (reviewed in Shively and Beatty, 1985). It is a membrane-bound glycoprotein that is also released into the blood and other body fluids. For this reason, not only are post-operative CEA serum levels a useful parameter for monitoring recurrent tumors, but the presence of CEA on the surface of tumor cells also offers the possibility of localizing tumors with CEA-specific, radiolabelled antibodies and targetting in immunotherapy. CEA is not a tumor-specific antigen, but it has only a low steady-state concentration in normal tissues.

CEA is a member of a family of glycoproteins with variable expression patterns. CEA-related antigens are present in different normal tissues: for example, non-specific crossreacting antigen (NCA) is found in granulocytes, while biliary glycoprotein (BGP) is present in bile (reviewed in Thompson et al., 1991). The protein backbone, as determined by protein microsequencing or as derived through molecular cloning, reveals high sequence similarity among individual members of the CEA family. A gene family exists, comprising at least 22 genes (Khan et al., 1992) closely clustered on the long arm of chromosome 19 (Thompson et al., 1991). Sequence comparisons allow a division into 2 main sub-groups, one encoding the classical CEA and cross-reacting antigens, the other the pregnancy-specific glycoproteins (PSGs) expressed in increasing amounts by the placenta during pregnancy.

A major problem in studying the expression of CEA-related antigens at the protein level has been the lack of wellcharacterized antibodies that are specific for individual antigen species. Through molecular cloning and the creation of stable transfectants expressing individual members of the CEA family, panels of monoclonal antibodies (MAbs) have been tested using FACscan analyses to better define their specificities (Daniel et al., 1993). The mass of sequence data produced in the last few years has also made it possible to study the expression patterns of individual members at mRNA level. Transcripts have been found by cDNA cloning studies and DNA/RNA hybridization (Northern) analyses for $17 \mathrm{CEA}$ related genes (reviewed in Thompson et al., 1991; Khan et al., 1992), yet the assignment of each CEA-related antigen to a specific gene remains difficult. Nevertheless, transcripts have been assigned to CEA (Oikawa et al., 1987), NCA-50/90 (Neumaier et al., 1988), NCA-95 (Berling et al., 1990) and BGP (Hinoda et al., 1988).

Although the CEA cross-reacting antigens are expressed in various normal tissues, they may also be useful as tumor markers. For example, PSGs have been used as markers for choriocarcinomas (Sakuragi, 1982). A 3.9-kb transcript for BGP has been reported not only in normal human hepatocytes but also in 16/21 hepatocellular carcinomas (Hinoda et al., 1990). NCA but not CEA transcripts are more prevalent in benign adenomas and colonic carcinomas than in adjacent normal mucosa, indicating the potential use of $\mathrm{NCA}$ as a marker for progression towards malignancy of colonic tumors (Chi et al., 1991). In contrast, CEA and BGP transcripts have recently been reported to be more prevalent in certain lung tumors than in corresponding normal tissues (Kim et al., 1992). We here examine in more detail the potential usefulness of individual members of the CEA family as tumor markers and attempt to determine their expression patterns more exactly.

It is usually necessary to use labelled DNA fragments to visualize transcripts using the DNA/RNA hybridization method. However, due to their high sequence similarities, it is not possible to differentiate all CEA-related transcripts with DNA fragment probes. On the basis of existing sequence data, we describe here the design and testing of oligonucleotide primer pairs to identify specific CEA-related transcripts in human tumors, using the reverse transcriptase/polymerase chain reaction (RT/PCR). The presence or absence of given transcripts has been correlated with the presence or absence of corresponding antigens as indicated by MAbs specific for CEA, NCA-50/90 and NCA-95.

${ }^{4}$ To whom reprint requests should be sent, at Institut für Immunbiologie der Universität, Stefan-Meier-Str. 8, D-79104 Freiburg im Breisgau, Germany. Fax: 49-761-203-4016.

\footnotetext{
Received: March 10, 1993 and in revised form April 26, 1993.
} 


\section{MATERIAL AND METHODS \\ Oligonucleotide primers}

Sequence comparisons of individual CEA-gene-family members were carried out using published sequences to design oligonucleotides specific for CEA, NCA, BGP, CGM6, CGM1, CGM7 and for PSG1-PSG15 (Table I). A set of oligonucleotide primers was also synthesized for amplification of all known CEA-gene-family members. In order to achieve this, the program "Primer" was applied (Lucas et al., 1991). This program was developed in our group for the comparison and identification of specific nucleotide sequences from gene families.

\section{Source of $c D N A$ clones}

A full-length CEA cDNA clone was constructed (Pèlegrin et al., 1992), sub-cloned into a Bluescript $\mathrm{M} 13^{+} \mathrm{KS}$ vector (Stratagene, La Jolla, CA) and linearized prior to PCR analysis by HindIII digestion. A 2-kb EcoRI fragment of the cDNA clone pNCA1 (Neumaier et al., 1988) containing the coding region of NCA and a BamHI/EcoRI fragment from the partial BGP cDNA clone 18 (Hinoda et al., 1988), both kindly made available by Dr. J. Shively (Beckman Research Institute, Duarte, $\mathrm{CA}$ ) were also used for primer specificity testing. For CGM6, a full-length cDNA clone in the Bluescript vector (Berling et al., 1990) was linearized using EcoRI, as was the PSG3 cDNA clone pSP-1i (Rooney et al., 1988), which was a kind gift from Dr. N. Hardman (Ciba-Geigy, Basel, Switzerland). A CGM7 cDNA clone which was provided by Dr. M. Kuroki (Fukuoka, Japan) and a cDNA clone containing the complete coding region of CGM1a (Nagel et al., 1993) were also used for primer testing.

Tumor source, RNA extraction and polymerase-chain-reaction conditions

The tumors located in the brain and relevant clinical data were kindly provided by Dr. Seeger (Department of Neurosurgery, University Hospital, Freiburg, Germany). The gynecological tumors and clinical data were from Dr. T. Bauknecht (Department of Gynecology, University Hospital, Freiburg, Germany) and Dr. J. Arsenau (Department of Pathology,
Royal Victoria Hospital, Montreal, Canada). Tumor material was quick-frozen in liquid nitrogen and stored at $-70^{\circ} \mathrm{C}$ prior to RNA isolation from 0.5 to $1 \mathrm{~g}$ tumor tissue, using the acid phenol extraction method described by Chomczynski and Sacchi (1987) or the guanidinium-isothiocyanate extraction procedure (Sambrook et al., 1989). Tissues were first ground under liquid nitrogen with a pestle and mortar and finely homogenized in extraction buffer using a tight-fitting glass/ Teflon homogenizer.

Reverse transcription and polymerase chain reactions were slightly modified after Sambrook et al. (1989), as described in Lucas et al. (1991). For the reverse transcription step, either 25 pmole of the selected $3^{\prime}$ oligonucleotide or later 50 pmole of a random hexamer mixture (Pharmacia, Uppsala, Sweden) were used to prime first-strand DNA synthesis from $200 \mathrm{ng}$ or $1 \mu \mathrm{g}$ of total RNA. The optimized system utilized 50 pmole of random hexamer and $1 \mu \mathrm{g}$ of total RNA for reverse transcription. The specific oligonucleotides (50 pmole each) were added after the reverse-transcription step, and 30 amplification cycles were applied using optimal annealing temperatures (Table I) for the given primer sets ( $15 \mathrm{sec} / \mathrm{step})$.

Prior to testing for the presence of CEA-related transcripts, the integrity of the RNA extracted from various tumors was determined. This control was to rule out false negative results where the RNA may be degraded, or reverse transcription and/or DNA amplification inhibited due to the presence of impurities. It was achieved by PCR using a primer set to amplify $\beta$-actin transcripts. This was tested both with and without reverse transcriptase, so as to avoid false positive signals due to contaminating DNA in the preparations. It is known that a large number of processed $\beta$-actin pseudogenes exists ( $\mathrm{Ng}$ et al., 1985), and, in the absence of the reverse transcription step, positive signals of the same size as from the mRNA reveal DNA contamination. However, even in the presence of contamination, differences in signal strength or banding pattern can still be used to confirm RNA integrity. As no intronless pseudogenes have so far been discovered for the CEA-gene family, DNA contamination should not create problems with the PCR. In the search for another ubiquitously

TABLE I - PRIMER SETS FOR SPECIFIC AMPLIFICATION OF CEA-RELATED AND CONTROL TRANSCRIPTS BY RT/PCR

\begin{tabular}{|c|c|c|c|c|c|c|c|}
\hline Transcripts & Primer pairs & Sequences & Exon & $\begin{array}{l}\text { Position from } \\
\text { ATG [nc] }\end{array}$ & $\begin{array}{c}\text { Fragment } \\
\text { length } \\
\text { [bp] }\end{array}$ & $\mathrm{T}_{\text {annealing }}\left[{ }^{\circ} \mathrm{C}\right]$ & Reference \\
\hline$\beta$-actin & $\begin{array}{l}\text { PCRßactin5' } \\
\text { PCRßactin3' }\end{array}$ & $\begin{array}{l}\text { 5'-ACGGCTGCTTCCAGCTCCTC-3' } \\
\text { 5'-AGCCATGCCAATCTCATCTTGT-3' }\end{array}$ & $\stackrel{3}{3}$ & $\begin{aligned} 685 & \Rightarrow 706 \\
1188 & \Rightarrow 1209\end{aligned}$ & 525 & 64 & $\begin{array}{l}\text { Ponte et al., 1984; } \\
\text { Nget al., 1985 }\end{array}$ \\
\hline c-abl & $\begin{array}{l}\text { PCRABL1B5' } \\
\text { PCRABL3' }^{\prime}\end{array}$ & $\begin{array}{l}\text { 5'-ATGGGGCAGCAGCCTGGAAA-3' } \\
5^{\prime} \text {-GTGATGTAGTTGCTTGGGAC-3' }\end{array}$ & $\begin{array}{c}1 \mathrm{~b} \\
\text { internal }\end{array}$ & $\begin{aligned} 1 & \Rightarrow 20 \\
388 & \Rightarrow 407\end{aligned}$ & 407 & 60 & $\begin{array}{l}\text { Bernards et al., 1987; } \\
\text { Fainstein et al., } \\
1989\end{array}$ \\
\hline $\begin{array}{l}\text { All CEA- } \\
\text { family } \\
\text { transcripts }\end{array}$ & $\begin{array}{l}\text { PCRCEAall5' } \\
\text { PCRCEAall }^{\prime}\end{array}$ & 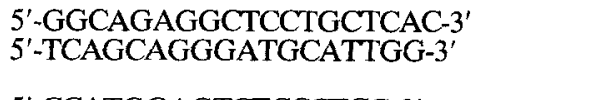 & $\begin{array}{l}5^{\prime} / \mathrm{L} \\
\mathrm{L} / \mathrm{N}\end{array}$ & $\begin{aligned} 44 & \Rightarrow 62 \\
308 & \Rightarrow 325\end{aligned}$ & 282 & 56 & $\begin{array}{l}\text { listed in Thompson } \\
\quad \text { et al., } 1991\end{array}$ \\
\hline CEA & $\begin{array}{l}\text { PCRCEA-5' } \\
\text { PCRCEA-3' }\end{array}$ & 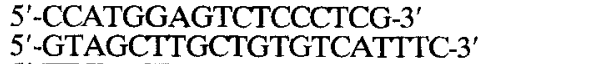 & $\begin{array}{l}5^{\prime} / \mathrm{L} \\
\mathrm{A} 1\end{array}$ & $\begin{aligned}-2 & \Rightarrow 15 \\
620 & \Rightarrow 639\end{aligned}$ & 641 & 56 & Oikawa et al., 1987 \\
\hline $\mathrm{NCA}$ & $\begin{array}{l}\text { PCRNCA-5' } \\
\text { PCRNCA-3' }\end{array}$ & 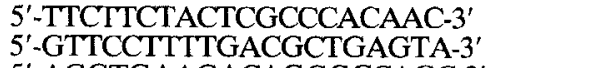 & $\mathrm{L} / \mathrm{N}$ & $\begin{array}{l}152 \Rightarrow 171 \\
606 \Rightarrow 625\end{array}$ & 474 & 58 & Neumaier et al., 1988 \\
\hline BGP & $\begin{array}{l}\text { PCRBGP-5' } \\
\text { PCRBGP-3' }\end{array}$ & $\begin{array}{l}\text { 5'-AGGTGAAGACAGGGCCAGC-3' } \\
\text { 5'-ATGTTCCATTGATAAGCCAG-3' }\end{array}$ & $\begin{array}{l}5^{\prime} \cdot \mathrm{L} \\
\mathrm{B} 1\end{array}$ & $\begin{aligned}-29 & \Rightarrow-11 \\
811 & \Rightarrow 830\end{aligned}$ & 859 & 56 & Hinoda et al., 1988 \\
\hline CGM6 & 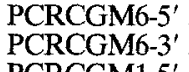 & $\begin{array}{l}5^{\prime} \text {-ATCTCAGCCCCTTCCTGCAG-3' } \\
5^{\prime} \text {-CAGTTGTAGCCACGAGGGTC-3' }\end{array}$ & $5^{\prime} / \mathrm{L}$ & $\begin{aligned} 10 & \Rightarrow 29 \\
181 & \Rightarrow 200\end{aligned}$ & 191 & 64 & Berling et al., 1990 \\
\hline CGM1 & $\begin{array}{l}\text { PCRCGM1-5' } \\
\text { PCRCGM1-3' }\end{array}$ & $\begin{array}{l}\text { 5'-GGAATTCCTGGAGCCCAGGCTCTTT-3' }^{\prime} \text { '-CTGTCGAGG TCTCCACA-3' }\end{array}$ & $\begin{array}{l}5^{\prime} / \mathrm{L} \\
3^{\prime}-\mathrm{UTTR}\end{array}$ & $\begin{aligned}-56 & \Rightarrow-35 \\
920 & \Rightarrow 936\end{aligned}$ & 992 & 54 & Kuroki et al., 1991 \\
\hline CGM7 & $\begin{array}{l}\text { PCRCEAall5' } \\
\text { PCRCGM7-3' }\end{array}$ & 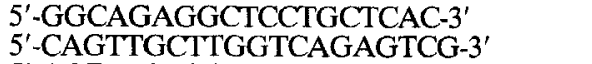 & $5^{\prime} / \mathrm{L}$ & $\begin{aligned} 44 & \Rightarrow 62 \\
387 & \Rightarrow 406\end{aligned}$ & 363 & 58 & Kuroki et al., 1991 \\
\hline $\begin{array}{l}\text { All PSG } \\
\text { transcripts }\end{array}$ & $\begin{array}{l}\text { PCRPSGall5' } \\
\text { PCRPSGall3' }\end{array}$ & $\begin{array}{l}\text { 5'-AGTTTCTGGATCCTAGGCT-3' } \\
\text { 5'-GATGTAATGTAATGGTAGAGG-3' }\end{array}$ & $\begin{array}{c}5^{\prime} / \mathrm{L} \\
\mathrm{N}\end{array}$ & $\begin{aligned} &-56 \Rightarrow-38 \\
& 222 \Rightarrow 242 \\
&\end{aligned}$ & 298 & 56 & $\begin{array}{l}\text { listed in Thompson } \\
\text { et al., } 1991\end{array}$ \\
\hline
\end{tabular}

The positions of the CEAall and PSGall primer sets are based on the sequences for CEA (Oikawa et al., 1987) and PSG3 (Rooney et al., 1988), respectively. The primer PCRCGM1-5' has an EcoRI linker at the $5^{\prime}$-end (bold print indicates extended sequence not found in CGM1). For exon nomenclature of CEA-gene family, see Thompson et al. (1991). nc, nucleotides; bp, base pairs. 
expressed control mRNA, where no processed pseudogenes exist, we synthesized a primer set (Table I) for the amplification of the $1 \mathrm{~b}$ transcripts for the proto-oncogene $\mathrm{c}-a b l$ (Bernards et al., 1987).

For each primer set, positive and negative controls were included in the RT/PCR reaction. As a negative control, water instead of RNA was used in all cases. For the CEAall, CEA and NCA sets, we initially used RNA from a human colonic tumor and later from an ovarian mucinous tumor as positive controls. Total RNA from leukocytes of a chronic myeloid leukemia patient and later RNA from transfectants expressing the respective CEA-family members were the positive controls for the BGP, CGM1, CGM6 and CGM7 primer sets. Alternatively, for the BGP set, RNA from the human adenocarcinoma cell line HT29 was also used. The positive control for the PSGall primer set was total RNA from a term placenta.

\section{Transfer of DNA and oligonucleotide hybridization}

After size separation of DNA fragments on agarose gels, alkaline transfer to Biodyne B membranes (PALL, Dreieich, Germany) was carried out according to Chomczynski and Qasba (1984). The following oligonucleotides were synthesized as specific internal probes to unequivocally identify each amplification product:
CEA/PSGal!

CEA-specific

NCA-specific

BGP-specific

CGM6-specific

CGM7-specific

PSGall-specific

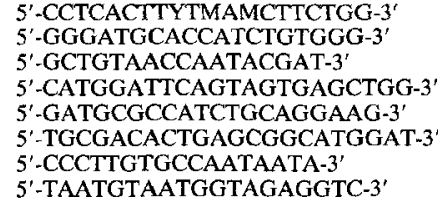

5'-TAATGTAATGGTAGAGGTC-3'

(max. 1 mismatch) ( $\geq 3$ mismatches) ( $\geq 3$ mismatches) ( $\geq 2$ mismatches) ( $\geq 2$ mismatches) ( $\geq 3$ mismatches) $(\geq 5$ mismatches $)$ ( $\geq 5$ mismatches)
The sequence source for each oligonucleotide is as listed in Table I. The minimal number of mismatches to other members of the CEA gene family are indicated in brackets. The CEA/PSGall oligonucleotide was designed to hybridize with all family members with maximally 1 mismatch. For the PSGall-specific probe, maximally 2 mismatches were found to all PSG sub-group members. Oligonucleotides were $5^{\prime}$-endlabelled, hybridized (Sambrook et al., 1989) and washed to approximately $4^{\circ} \mathrm{C}$ below their theoretical melting temperatures, as calculated according to Lathe (1985), in $6 \times \operatorname{SSPE}(1 \times$ SSPE is $0.18 \mathrm{M} \mathrm{NaCl}, 10 \mathrm{mM} \mathrm{Na}$-phosphate, $\mathrm{pH} 7.4$, and $1 \mathrm{mM}$ EDTA), $0.1 \%$ SDS. The maximal wash temperatures for the CEA/PSGall- and PSGall-specific oligonucleotides took into account a maximum of 1 or 2 mismatches respectively.

\section{Immunohistochemistry}

Frozen tumor material was embedded in Tissue Tek Freeze medium (Reichert-Jung, Vienna, Austria) and sectioned on a cryomicrotome (Model 2700 Frigocut, Reichert-Jung). Sections of 7 to $10 \mu \mathrm{m}$ were stored on poly (L-lysine) coated slides at $-70^{\circ} \mathrm{C}$, and parallel sections were stained with hemalaun/ eosin for identification of tissue structure. Prior to freezing, the sections were dried under vacuum at room temperature or $30^{\circ} \mathrm{C}$ for 1 to $2 \mathrm{hr}$ and fixed for $10 \mathrm{~min}$ in acetone. Thawed sections were air-dried and re-hydrated in PBS. Endogenous peroxidase activity was blocked by incubation in $0.3 \% \mathrm{H}_{2} \mathrm{O}_{2}$ in methanol for $30 \mathrm{~min}$. Pre-incubation with $3 \%$ ovalbumin, Grade II (Sigma, St. Louis, MO) was carried out before the antibody incubations were made. Monoclonal antibodies (Daniel et al., 1993) were used to differentiate CEA (26/3/13), NCA-50/90 (9A6FR) and NCA-95 (80H3) using the avidinbiotin (ABC) procedure and a Vectastain kit (Vector, Burlingame, CA). The first antibodies were diluted to a concentration of $5 \mu \mathrm{g} / \mathrm{ml}$ PBS $(137 \mathrm{mM} \mathrm{NaCl}, 2.7 \mathrm{mM} \mathrm{KCl}, 8.1 \mathrm{mM}$ $\mathrm{Na}_{2} \mathrm{HPO}_{4}, 1.8 \mathrm{mM} \mathrm{KH}_{2} \mathrm{PO}_{4}, \mathrm{pH} 7.4$ ) for incubation. The rabbit anti-mouse IgG bridge antibodies were used at a dilution of 15 $\mu \mathrm{g} / \mathrm{ml}$ PBS and the avidin-biotin complex was diluted 1:125 in PBS. Counterstaining was carried out with hemalaun. Positive controls for CEA and NCA-50/90 were colonic tumor, or normal colon sections. For NCA-95, the positive control was a human blood smear. As negative control, the first antibody was either omitted from the buffer or replaced by mouse IgG. The specificity of the antibodies has been tested elsewhere in FACscan analyses, using stable transfectants expressing CEA, NCA-50/90, CGM6 (NCA-95), BGP, CGM1 and CGM7 (Daniel et al., 1993).

\section{RESULTS}

Development of a PCR system for identification of transcripts derived from $C E A$-gene-family members

In order to synthesize specific or common oligonucleotide primer sets it was necessary to compare all known CEA-genefamily DNA sequences. To be certain that the amplification products originated from tumor RNA and not from contaminating genomic DNA, the $5^{\prime}$ and $3^{\prime}$ oligonucleotides were chosen from different exons (Table I).

The different primer sets were then tested and their annealing temperatures optimized for their specificities against various CEA-related cDNAs (Fig. 1). One primer set (PCRCEAall5' $/$ PCRCEAall ${ }^{\prime}$ ') was designed to amplify mRNA of all CEA-gene-family members and an amplification product of the expected size was found for all cDNA clones tested (Fig. $1 a$ ). In all cases, amplification fragments of the expected sizes were seen (Table I). Despite theoretical specificity of the primer sets designed to amplify only individual members of the CEA-gene family, when tested against all cDNA clones, some cross-amplification with products of the same or different sizes was found Fig. 1, $c-g$. However, higher specificity was achieved by transferring the amplification products to nylon membranes and by hybridization with internal oligonucleotides specific for each product with their respective cDNA templates.

The c-abl primer set as a control for the integrity of the RNA was tested against total genomic DNA where no amplification signals were seen (data not shown) and optimized for amplification of total RNA extracts. In order to get visible signals for the c-abl transcript, $1 \mu \mathrm{g}$ of total RNA per PCR was needed. For determination of the optimal amounts of total RNA needed to give visible signals in the PCR reaction for CEArelated transcripts, variable amounts of RNA from a human colon adenocarcinoma were tested. Although signals were still visible with 1 to $10 \mathrm{ng}$ RNA for CEA and NCA, we used $200 \mathrm{ng}$ total RNA for the first screenings. However, after comparing the results gained with the immunohistochemical staining patterns from the same tumors, it became obvious that the latter showed greater sensitivity. For this reason, and for uniformity with the c-abl control, we then increased the amount of total RNA to $1 \mu \mathrm{g} /$ reaction.

Once the PCR conditions had been optimized, total RNA from selected tumors expected to be either positive (various carcinomas) or negative (different brain tumors), was tested for the presence of CEA-related transcripts (Table II). In order to avoid screening each RNA with all primer sets, after determining the integrity of the RNA, a primer set was used which should amplify all CEA-related transcripts (Fig. 1a). Those RNAs that were negative with this primer set were not further tested with specific oligonucleotides. Three carcinomas revealed expression products of the expected size for CEA and NCA: a squamous carcinoma of the lung, an adenocarcinoma of the pancreas (these were included as positive controls) and an adenocarcinoma located in the nasal sinuses. No transcripts were found for BGP, CGM6 or the PSG sub-group. CGM1 and CGM7 transcripts were not determined. As expected, none of the neuroepithelial $(n=4)$ or the mesenchymal brain tumors 


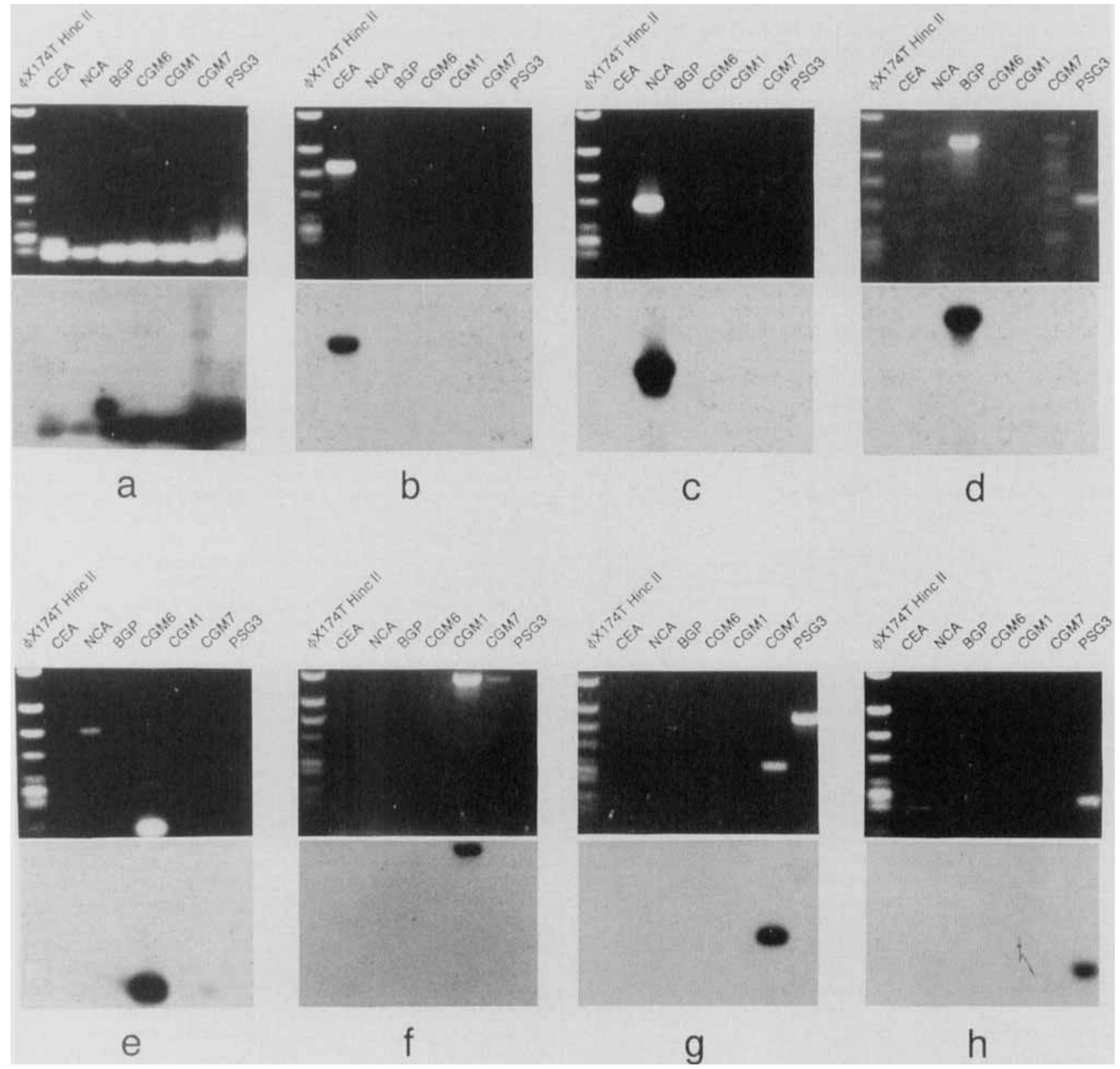

FIGURE 1 -Specificity control of primer sets designed to amplify transcripts from individual CEA-gene-family members. PCR amplification was carried out using cDNA clones as templates from individual members of the CEA-gene family (listed above). A HincII digest of bacteriophage $\phi X 174 \mathrm{~T}$ was used as a size marker. The following oligonucleotide primer sets (listed in Table I) were used: $a$, PCRCEAall; $b$, PCRCEA; $c$, PCRNCA; $d$, PCRBGP; $e$, PCRCGM6; $f$, PCRCGM1; $g$, PCRCGM7; $h$, PCRPSGall. Ethidium-bromide staining of the DNA after separation on a $1.8 \%$ agarose gel is shown in the upper section and the hybridization results in the lower section of each sub-figure, using the following $5^{\prime}$-end-labeled, internal oligonucleotides: $a$, CEA/PSGall; $b$, CEA-specific; $c$, NCA-specific; $d$, BGP-specific; $e$, CGM6-specific; $f$, CGM1-specific; $g$, CGM7-specific; $h$, PSGall-specific.

$(n=6)$ tested contained transcripts for any CEA-gene-family member (Table II).

\section{Identification of CEA-related transcripts in gynecological tumors}

A larger-scale RT/PCR-screening was carried out on 63 different gynecological tumors (Fig. 2; Table III). The integrity of the RNA was first tested using the $\beta$-actin primer set, with and without the reverse transcription step. In some cases, DNA contamination revealed amplification products with and without reverse transcription (Fig. $2 d$ : colon-tumor metastasis). However, the larger fragment representing the active $\beta$-actin gene with intervening intron sequences was visible only in the absence of reverse transcription. As this fragment usually disappeared after inclusion of reverse transcription, intact RNA must also be present in such RNA samples. Parallel controls with the c-abl primer set confirmed these results (data not shown). In cases where the RNA was intact, the expression of CEA and CEA-related transcripts was 
TABLE II - DETECTION OF CEA-GENE-FAMILY TRANSCRIPTS IN SELECTED TUMORS USING AN RT/PCR ASSAY

\begin{tabular}{|c|c|c|c|c|c|c|c|c|c|}
\hline $1 \mu g$ total RNA & $\mathrm{c}-\mathrm{abl} / \beta$-actin & CEAall & CEA & $\mathrm{NCA}$ & BGP & CGM6 & CGM1 & CGM7 & PSGall \\
\hline \multicolumn{10}{|l|}{ Epithelial tumors } \\
\hline Breast carcinomas & $2 / 2$ & $0 / 2$ & - & & - & - & - & - & - \\
\hline Pancreas adenocarcinoma & $1 / 1$ & $1 / 1$ & $1 / 1$ & $1 / 1$ & $0 / 1$ & $0 / 1$ & $\overline{\text { nd }}$ & $\overline{\text { nd }}$ & $\overline{0 / 1}$ \\
\hline Lung squamous carcinoma & $1 / 1$ & $1 / \hat{1}$ & $1 / 1$ & $1 / 1$ & $0 / 1$ & $0 / 1$ & nd & dn & $0 / 1$ \\
\hline \multicolumn{10}{|l|}{ Neuro-epithelial tumors } \\
\hline $\begin{array}{l}\text { Astrocytomas } \\
\text { Oligodendroglioma }\end{array}$ & $2 / 2$ & $0 / 2$ & - & - & - & - & - & $\longrightarrow$ & - \\
\hline Oligodendroglioma & $1 / 1$ & $0 / 1$ & - & 一 & - & - & - & - & - \\
\hline $\begin{array}{l}\text { Glioblastoma multiforma } \\
\text { Intracranial epithelial tumor }\end{array}$ & \multicolumn{7}{|c|}{ Intracranial epithelial tumor } & & - \\
\hline Nasal sinus adenocarcinoma & $1 / 1$ & $1 / 1$ & $1 / 1$ & $1 / 1$ & $0 / 1$ & $0 / 1$ & nd & nd & $0 / 1$ \\
\hline \multicolumn{10}{|l|}{ Mesenchymal brain tumors } \\
\hline Meningeomas & $4 / 4$ & $0 / 4$ & - & - & - & - & - & - & - \\
\hline Hemangioblastoma & $1 / 1$ & $0 / 1$ & - & - & - & - & - & - & - \\
\hline Non-Hodgkin lymphoma & $1 / 1$ & $0 / 1$ & - & - & - & - & - & - & - \\
\hline \multicolumn{10}{|l|}{ Metastases in brain } \\
\hline Lung squamous carcinoma & $1 / 1$ & $0 / 1$ & - & - & - & - & - & - & - \\
\hline Ovarian carcinoma & $1 / 1$ & $0 / 1$ & - & - & - & - & - & - & - \\
\hline
\end{tabular}

nd, not determined

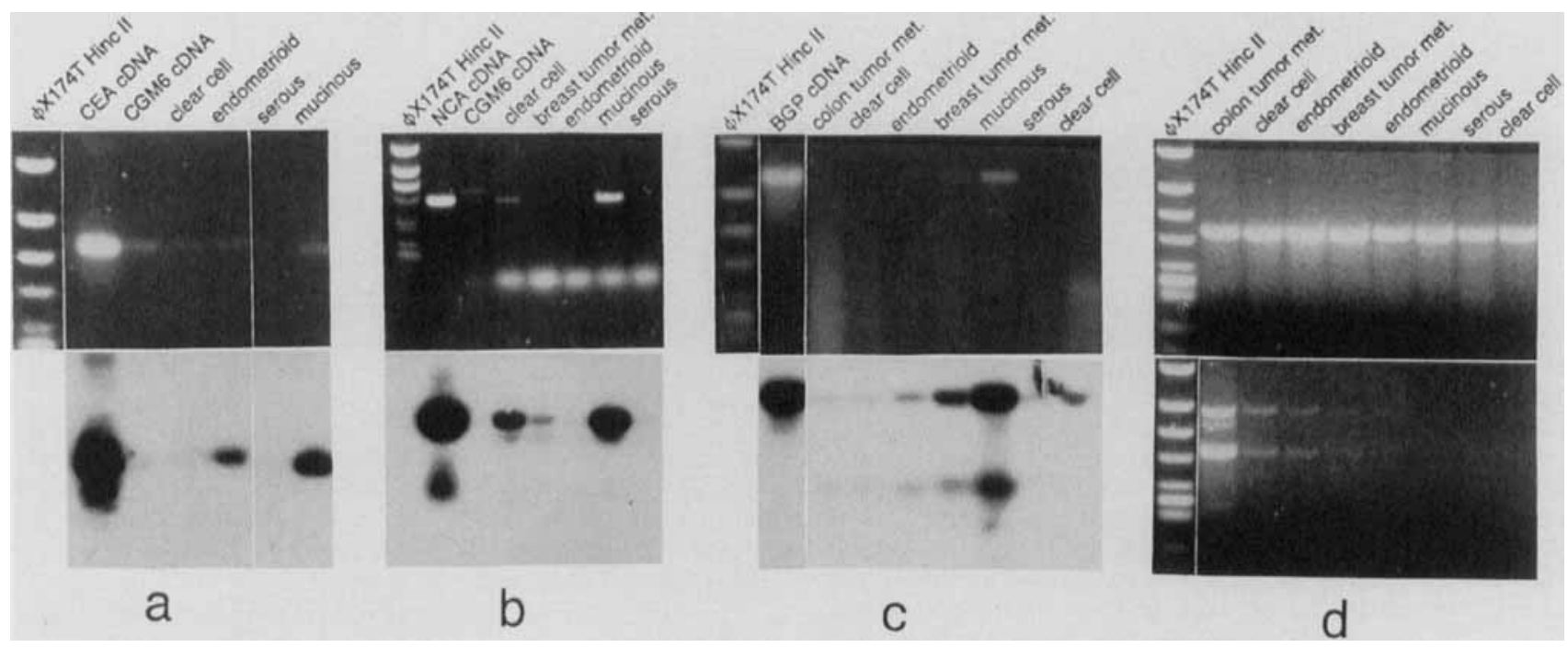

FIGURE 2 - Identification of CEA-related transcripts in ovarian tumors. RNA isolated from different tumors was reverse transcribed and PCR-amplified using the following oligonucleotide primer sets: $a$, PCRCEA; $b$, PCRNCA; $c$, PCRBGP; $d$, PCR $\beta$ actin, to specifically amplify CEA, NCA, BGP and $\beta$-actin transcripts respectively. Examples are shown from different tumor types (listed above) along with positive controls from respective cDNA clones. The upper part of the figure shows ethidium-bromide staining of DNA gels; the lower part shows hybridization results with the following internal oligonucleotide probes: $a$, CEA-specific; $b$, NCA-specific; $c$, BGP-specific. In $d$, the upper part of the figure is with reverse transcription and the lower part is without this step.

investigated. As seen in Table III, co-expression of CEA, NCA and occasionally BGP transcripts, but of no other CEA-genefamily member, was found in the mucinous ovarian carcinomas $(\mathrm{n}=10)$, whereas CEA-related transcripts were found only in $4 / 12$ serous, $4 / 7$ endometrioid and $2 / 7$ clear-cell ovarian carcinomas. From $200 \mathrm{ng}$ total RNA, benign leiomyomas of the uterus revealed no CEA-related transcripts $(n=7)$, whereas some endometrial adenocarcinomas as well as carcinomas of the cervix expressed transcripts for CEA $(2 / 6)$, NCA $(2 / 6)$ and BGP $(2 / 6)$. For unequivocal identification of the different amplification products, the fragments were transferred to nylon membrane and hybridized at high stringency with transcript-specific oligonucleotides (Fig. $2 a-c$ ). Although the lower hybridization signal seen in Figure $2 c$ corresponds in size with the cross-amplification product seen with this BGP primer set in the ethidium-bromide-stained gel using the PSG3 cDNA as a control (Fig. 1d), it does not represent a PSG, since the same tumours as shown in Figure $2 c$ were negative when tested with the PSGall primer set (data not shown). None of the tumors examined revealed the presence of transcripts for CGM1, CGM6, CGM7 or any PSG-sub-family member in the conditions used (data not shown).

\section{Expression of CEA, NCA-50/90 and NCA-95 in gynecological tumors using specific $M A b$ s}

Apart from the internal positive and negative controls, the efficacy of the PCR system was tested at the antigen level using specific MAbs in standard immunohistochemical studies to differentiate CEA (Mab 26/3/13), NCA-50/90 (Mab 9A6FR) and NCA-95 (Mab 80H3). A typical staining pattern of these 3 Mabs is shown on serial sections of an ovarian mucinous carcinoma in Figure 3. The CEA- (Fig. 3a) and NCA50-90(Fig. $3 b$ ) specific antibodies both reveal positive staining of tumor cells, whereas NCA-95 is present only in granulocytes (Fig. $3 c$ ) and not in tumor cells in this example. The negative control reveals no unspecific background staining (Fig. $3 d$ ). 
TABLE III - DETECTION OF CEA-GENE-FAMILY TRANSCRIPTS IN GYNECOLOGICAL TUMORS USING AN RT/PCR ASSAY

\begin{tabular}{|c|c|c|c|c|c|c|c|c|c|}
\hline & $\begin{array}{c}\mathrm{c}-\mathrm{abl} / \\
\beta \text {-actin }\end{array}$ & CEAall & CEA & NCA & BGP & CGM6 & CGM1 & CGM7 & PSGall \\
\hline \multicolumn{10}{|l|}{ Ovarian tumors ( $1 \mu \mathrm{g}$ total RNA) } \\
\hline $\begin{array}{l}\text { Benign tumors } \\
\text { Cystoma }\end{array}$ & $1 / 1$ & $0 / 1$ & - & \multicolumn{2}{|c|}{ Benjgn tumors } & 一 & - & - & - \\
\hline \multicolumn{10}{|l|}{ Malignant tumors } \\
\hline \multicolumn{10}{|l|}{ Carcinomas } \\
\hline Serous & $12 / 16$ & $4 / 12$ & $1 / 4$ & $1 / 4$ & $1 / 4$ & $0 / 4$ & $0 / 4$ & $0 / 4$ & $0 / 4$ \\
\hline Mucinous & $10 / 10$ & $10 / 10$ & $10 / 10$ & $10 / 10$ & $4 / 10$ & $0 / 10$ & $0 / 10$ & $0 / 10$ & $0 / 10$ \\
\hline Endometrioid & $7 / 10$ & $4 / 7$ & $1 / 4$ & $1 / 4$ & $1 / 4$ & $0 / 4$ & $0 / 4$ & $0 / 4$ & $0 / 4$ \\
\hline Clear-cell & $7 / 8$ & $2 / 7$ & $2 / 2$ & $2 / 2$ & $1 / 2$ & $0 / 2$ & $0 / 2$ & $0 / 2$ & $0 / 2$ \\
\hline Sarcoma & $1 / 1$ & $0 / 1$ & - & - & - & - & 一 & - & 一 \\
\hline Teratomas & $2 / 2$ & $0 / 2$ & - & - & 一 & - & - & - & - \\
\hline \multicolumn{10}{|l|}{ Metastases in ovary } \\
\hline Colon carcinomas & $3 / 3$ & $2 / 3$ & $1 / 2$ & $1 / 2$ & $1 / 2$ & $0 / 2$ & $0 / 2$ & $0 / 2$ & $0 / 2$ \\
\hline Stomach carcinoma & $1 / 1$ & $1 / 1$ & $1 / 1$ & $1 / 1$ & $1 / 1$ & $0 / 1$ & $0 / 1$ & $0 / 1$ & $0 / 1$ \\
\hline Breast carcinoma & $1 / 1$ & $1 / 1$ & $1 / 1$ & $1 / 1$ & $1 / 1$ & $0 / 1$ & $0 / 1$ & $0 / 1$ & $0 / 1$ \\
\hline \multicolumn{10}{|c|}{ Uterine tumors ( $200 \mathrm{ng}$ total RNA) } \\
\hline \multicolumn{10}{|c|}{ Benign tumors } \\
\hline \multicolumn{10}{|l|}{ Malignant tumors } \\
\hline $\begin{array}{l}\text { Endometrial } \\
\text { adenocarcinomas }\end{array}$ & $6 / 6$ & $4 / 6$ & $2 / 4$ & $2 / 4$ & $2 / 4$ & $0 / 4$ & $0 / 4$ & $0 / 4$ & $0 / 4$ \\
\hline \multicolumn{10}{|c|}{ Cervical tumors (200 ng total RNA) } \\
\hline $\begin{array}{l}\text { Carcinomas } \\
\text { Other tumors ( } 200 \mathrm{ng} \text { total RN }\end{array}$ & $3 / 3$ & $2 / 3$ & $2 / 2$ & $2 / 2$ & $1 / 2$ & $0 / 2$ & $0 / 2$ & $0 / 2$ & $0 / 2$ \\
\hline $\begin{array}{l}\text { Vulvar intra-epithelial } \\
\text { neoplasia }\end{array}$ & $1 / 1$ & $1 / 1$ & $1 / 1$ & $1 / 1$ & $1 / 1$ & $0 / 1$ & $0 / 1$ & $0 / 1$ & $0 / 1$ \\
\hline Fallopian-tube carcinoma & $1 / 1$ & $0 / 1$ & $0 / 1$ & - & - & - & - & - & - \\
\hline
\end{tabular}

The total results of the immunohistochemical analyses are compared with those from PCR studies for individual tumors in Table IV. The results for CEA expression at the mRNA and the antigen level correlate well in 17 from 19 ovarian tumors analyzed. For NCA-50/90, the tumors positive at the mRNA level were also positive at the antigen level. However, NCA$50 / 90$ and NCA-95 antigen were found in $5 / 19$ and $4 / 19$ tumors, respectively, that were apparently negative for the corresponding transcripts. In all those cases, these NCA species were located focally in only a few tumor cells $(<5 \%$ total tumor cells) and/or were present within granulocytes (Fig. $3 c$ ) in areas of inflammation or in non-identifiable cells. The number of granulocytes or non-identifiable cells stained was often equal to or greater than the number of positive tumor cells.

\section{DISCUSSION}

Using a computer program specifically written for this purpose (Lucas et al., 1991), we have synthesized and tested oligonucleotide primer sets against individual CEA-related cDNA clones that specifically amplify CEA, NCA, CGM6 (NCA-95), BGP, CGM1, CGM7 transcripts and a set that will amplify only members of the PSG sub-group. For other members of the CEA-gene family (CGM2, CGM8, 9, 10 and 11), no transcripts have so far been described. Furthermore, sequence analyses indicate that these members, apart from CGM2, contain stop codons and apparently represent pseudogenes (Khan et al., 1992). In future, the possibility of analyzing the expression of different splice products from individual genes, e.g., BGP or individual PSGs (Thompson et al., 1991), may also be taken into consideration in the design of new oligonucleotide primers. Furthermore, we are presently developing a CGM2-specific primer set in the search for transcripts from this gene.

The results gained in the analysis of selected tumors located in the brain revealed no CEA-related transcripts in neuroepithelial tumors nor in mesenchymal tumors. On the other hand, a poorly differentiated adenocarcinoma, which represents a primary nasal-sinus tumor, was shown to co-express CEA and NCA transcripts. These data support immunohistochemical studies carried out by Ang et al. (1990), who were unable to find CEA in 19 different brain primary tumors, whereas 6 brain metastases of primary tumors in the gastrointestinal tract were positive. Our results indicate that the sensitivity level of the RT/PCR is acceptable, in that the expected positivity and negativity based on published immunohistochemical data is reproduced.

Co-expression of NCA and CEA transcripts in ovarian mucinous adenocarcinomas was confirmed using MAbs specific against CEA and NCA-50/90. Other immunohistochemical investigations into the expression of CEA and NCA in ovarian tumors correlate well with our data (Motoyama et al., 1990). In brief, these investigations also identified CEA and NCA in all ovarian mucinous tumors. CEA and NCA were also present in a few endometrioid and clear-cell carcinomas, but rarely in serous ovarian carcinomas, although only a small percentage of tumor cells were positive. Co-expression of CEA and NCA is often found in other types of adenocarcinomas, e.g., colonic adenocarcinomas, as shown by DNA/RNA hybridization analyses (Chi et al., 1991). The immunohistochemical staining on serial sections has often, but not always, revealed that the same tumor cells express both CEA and NCA. It appears that co-regulation of gene expression may exist in such cases. The genes encoding CEA and NCA are directly adjacent on the long arm of chromosome 19 , being separated by only approximately $16 \mathrm{~kb}$ (data not shown). The coordination of expression of these genes could, therefore, be under the control of common cis-acting regulatory elements. However, in granulocytes, NCA but not CEA is expressed (Berling et al., 1990), indicating that gene-specific control elements must also exist. Indeed, in these investigations, some of the tumor cells expressed CEA but not NCA, or vice versa. In a few other tumors, the CEAall primer set yielded amplification products, but the specific primer sets were all negative (Table III). This suggests either amplification of unknown CEA-gene-family 

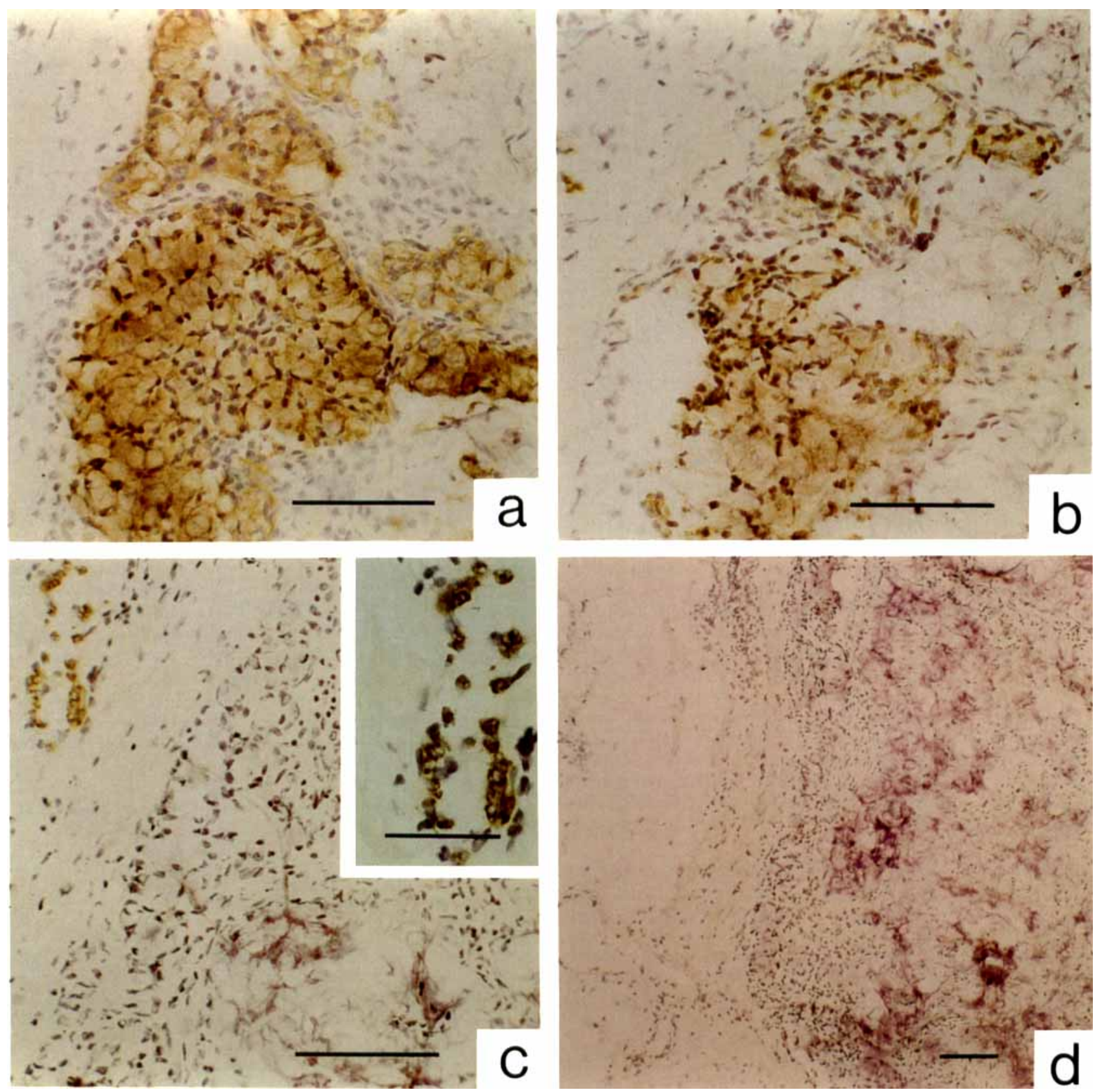

FIGURE 3 - Identification of CEA-related antigens in an ovarian mucinous adenocarcinoma by immunohistochemical staining. Serial tumor cryosections were incubated with specific MAbs to identify: $a, \mathrm{CEA}(26 / 3 / 13) ; b, \mathrm{NCA}-50 / 90$ (9A6FR); and $c$, NCA-95 (80H3). In $d$, lower magnification of the same area is shown in the negative control without first antibody. Although serial sections were analyzed, the region shown for NCA-95 (c) that stains granulocytes (see inset for stronger magnification) does not correspond exactly with those for CEA and NCA, but both regions are covered in the negative control $(d)$. Bars indicate $100 \mu \mathrm{m}(a-d), 50 \mu \mathrm{m}$ for inset in $(c)$.

members, or more probably, co-expression of more than one known family member at low levels where individual transcripts cannot be visualized at the present sensitivity level. However, confirmation of such low expression levels would be only of academic interest.

With 200 ng of total RNA, the sensitivity of the PCR system was lower than that of the immunohistochemical method, since in the serous, clear-cell and endometrioid ovarian carcinomas, as well as one mucinous carcinoma, no CEA-related transcripts were detected. The PCR conditions were then modified by increasing the amount of total RNA to $1 \mu \mathrm{g}$. Under these conditions, the immunochemical and PCR analyses yiclded more comparable results for expression of CEA-gene-family members. However, the focal staining seen in some tumor cells for NCA-50/90 and NCA-95 was still not detected with the PCR system. Although the PCR sensitivity may easily be further increased, problems could then arise with amplification of NCA, CGM1, CGM6, CGM7 and BGP transcripts present in granulocytes/leukocytes (Berling et al., 1990; Kuroki et al., 1991) that would lead to false positives. Indeed, the 
TABLE IV - COMPARISON OF RT/PCR-ASSAY WITH IMMUNOHISTOCHEMICAL DETECTION OF CEA-GENE-FAMILY MEMBERS IN OVARIAN TUMORS

\begin{tabular}{|c|c|c|c|c|c|c|}
\hline \multirow{2}{*}{ Tumor } & \multicolumn{3}{|c|}{ Immunohistochemistry } & \multicolumn{3}{|c|}{ RT/PCR assay } \\
\hline & CEA & NCA- $50 / 90$ & NCA -95 & CEA & $\mathrm{NCA}$ & CGM6 \\
\hline Mucinous & $(+)$ & + & - & + & + & - \\
\hline Mucinous & $(+)$ & + & - & + & + & - \\
\hline Mucinous & + & + & - & + & + & - \\
\hline Mucinous & + & + & - & + & + & - \\
\hline Mucinous & + & + & - & + & + & - \\
\hline Mucinous & + & + & - & + & + & - \\
\hline Serous & - & $(+)$ & - & $(+)$ & $(+)$ & - \\
\hline Serous & - & $(+)$ & $(+)$ & - & - & - \\
\hline Serous & - & $(+)$ & $(+)$ & - & - & - \\
\hline Serous & - & - & -1 & - & - & - \\
\hline Serous & - & - & - & - & - & - \\
\hline Endometrioid & - & - & - & - & - & - \\
\hline Endometrioid & - & - & - & - & - & - \\
\hline Endometrioid & $(+)$ & $(+)$ & - & + & - & - \\
\hline Endometrioid & - & $(+)$ & $(+)$ & - & $(+)$ & - \\
\hline Clear cell & - & $(+)$ & - & + & + & - \\
\hline Clear cell & - & $(+)$ & $(+)$ & - & - & - \\
\hline Clear cell & - & - & - & - & - & - \\
\hline Clear cell & - & $(+)$ & - & - & - & - \\
\hline
\end{tabular}

$(+)$ indicates only a weak signal in the RT/PCR assay or only $\leq 5 \%$ of the tumor cells stained positively.

number of granulocytes/leukocytes visualized in those tumors showing positivity only after immunohistochemical staining was often equal to or greater than the number of NCA-50/90or NCA-95-positive tumor cells. However, in the present PCR conditions, this has not been a problem; and in those tumors where NCA transcripts were found, immunohistochemical analysis confirmed that the tumor cells themselves were NCA-50/90- positive. Even without the latter control, where NCA products are found in the absence of amplification products for CGM6, as in all the tumors investigated here, it may be concluded that NCA is, indeed, expressed in the tumor cells and not in granulocytes, since steady-state CGM6 mRNA levels are generally higher than NCA mRNA levels in granulocytes (Berling et al., 1990).

In general, this RT/PCR assay provides a useful system for specific identification of transcripts for each CEA-related gene. This cannot be achieved at the antigen level for all family members, due to the lack of specific antibodies for each species, or through DNA/RNA hybridization studies, because many probes will cross-hybridize or be of limited sensitivity. A further advantage of this PCR system is that its unlimited sen- sitivity makes it feasible to carry out such studies on biopsy material (e.g., fine-needle aspirates) where the amounts of tumor tissue available for analysis are very small. In such cases, higher sensitivity may be attained by increasing the number of cycles rather than the RNA amounts, which will also be limiting.

The preliminary studies presented here indicate that not only CEA, but also NCA, may be a useful tumor marker for ovarian mucinous adenocarcinomas, whereas the expression of other CEA-family members is more limited or completely absent from the tumors investigated so far. These analyses will be continued and further optimized on other tumors in which expression of CEA and CEA-related antigens have been reported, e.g., tumors of the breast, lung and pancreas, and trophoblastic tumors.

\section{ACKNOWLEDGEMENTS}

We are grateful for the excellent technical assistance of Mrs. C. Steinki-Schwarz, Miss M. Ditter and Miss D. Glorieux. This work was supported by a grant from the Dr. Mildred Scheel Stiftung für Krebsforschung.

\section{REFERENCES}

Ang, L.C., Tayler, A.R., Bergin, D. and Kaufmann, J.C.E., An immunohistochemical study of papillary tumors in the central nervous system. Cancer, 65, 2712-2719 (1990).

Berling, B., Kolbinger, F., Grunert, F., Thompson, J.A., BromBACHER, F., BUCHEGGER, F., VON KLEIST, S. and ZIMMERMANN, W., Cloning of a carcinoembryonic-antigen-family member expressed in leukocytes of chronic-myeloid-leukaemia patients and bone marrow. Cancer Res., 50, 6534-6539 (1990).

Bernards, A., Rubin, C.M., Westbrook, C.A., Paskind, M. and BALTimore, D., The first intron in the human c-abl gene is at least 200 kilobases long and is a target for translocations in chronic myelogenous leukemia. Mol. cell. Biol., 7, 3231-3236 (1987).

Chi, K., Jessup, J.M. and Frazier, M.L., Predominant expression of mRNA coding for non-specific cross-reacting antigen in colorectal carcinomas. Tumor Biol., 12, 298-308 (1991).

ChOMCZYNSKI, P. and OASBA, P.K., Alkaline transfer of DNA to plastic membrane. Biochem. biophys. Res. Commun., 122, 340-344 (1984).

ChOMCZYNSKI, P. and SACCHI, N., Single-step method of RNA isola- tion by acid guanidinium thiocyanate-phenol-chloroform extraction. Anal. Biochem., 162, 156-159 (1987).

Daniel, S., NAGEl, G., Johnson, J., Lobo, F.M., HiRn, M., JanTSChefF, P., KuroKI, M., von KIEIST, S. and GrUNERT, F., Determination of the specifities of monoclonal antibodies recognizing members of the CEA family using a panel of transfectants. Int. J. Cancer, 55, 303-310 (1993).

Fainstein, E., Einat, M., Gokkel, E., Marcelle, C., Croce, C.M., GALE, R.P. and CANAANI, E., Nucleotide sequence analysis of human $\mathrm{abl}$ and bcr-abl cDNAs. Oncogene, 4, 1477-1481 (1989).

Hinoda, Y., Imai, K., Nakagawa, N., Ibayashi, Y., Nakano, T., PAXTON, R.J., ShIVELY, J.E. and YACHI, A., Transcription of biliary glycoprotein I in malignant and non-malignant human liver tissues. Int. J. Cancer, 45, 875-878 (1990).

Hinoda, Y., Neumaier, M., Hefta, S.A., Drzeniek, Z., Wagner, C., Shively, L., Hefta, L.J.F., Shively, J.E. and Paxton, R.J., Molecular cloning of a cDNA coding biliary glycoprotein. I: Primary structure of a glycoprotein immunologically cross-reactive with carcinoembryonic antigen. Proc. nat. Acad. Sci. (Wash.), 85, 6959-6963 (1988). 
Khan, W.N., Frängsmyr, L., Teglund, S., Israelsson, A., Bremer, $K$. and HAMmARSTRÖM, S., Identification of three new genes and estimation of the size of the carcinoembryonic antigen family. Genomics, 14, 384-390 (1992).

Kim, J., Kaye, F.J., Henslee, J.G., Shively, J.E., PARK, J.-G., LaI, S.-L., LinNoIlA, R.I., Mulshine, J.L. and GAZDAR, A.F., Expression of carcinoembryonic antigen and related genes in lung and gastrointestinal cancers. Int. J. Cancer, 52, 718-725 (1992).

Kuroki, M., Arakawa, F., Matsuo, Y., Oikawa, S., Misumi, Y., NAKAZATO, H. and MATSUOKA, Y., Molecular cloning of non-specific cross-reacting antigens in human granulocytes. J. biol. Chem., 266, 11810-11817(1991).

LATHE, R., Synthetic oligonucleotide probes deduced from amino acid sequence data: theoretical and practical considerations. J. mol. Biol., 183, 1-12 (1985).

Lucas, K., Busch, M., Mössinger, S. and Thompson, J.A., An improved microcomputer program for finding gene- or gene-familyspecific oligonucleotides suitable as primers for polymerase chain reactions or as probes. CABIOS, 7, 525-529 (1991).

Motoyama, T., Watanabe, H., Takeuchi, S., Watanabe, T., Gotoh, $S$. and OKAZAKI, E., Cancer antigen 125, carcinoembryonic antigen, and carbohydrate determinant $19-9$ in ovarian tumors. Cancer, 66, 2628-2635 (1990).

Nagel, G., Grunert, F., Kuijpers, T.W., Watt, S., Thompson, J. and ZIMMERMANN, W., Genomic organization, splice variants and expression of CGM1, a CD66-related member of the carcinoembryonicantigen-gene family. Europ. J. Biochem., 214, 27-35 (1993).

Neumaier, M., Zimmermann, W., Shively, L., Hinoda, Y., Riggs, A.D. and SHIVELY, J.E., Characterization of a cDNA clone for the non-specific cross-reacting antigen (NCA) and a comparison of NCA and carcinoembryonic antigen (CEA). J. biol. Chem., 263, 3202-3207 (1988).

Ng, S.Y., Gunning, P., Eddy, R., Ponte, P., Leavitt, J., Shows, T. and KEDES, L., Evolution of the functional human $\beta$-actin gene and its multi-pseudogene family: conservation of non-coding regions and chromosomal dispersion of pseudogenes. Mol. cell. Biol, 5, 2720-2732 (1985).

Oikawa, S., Nakazato, H. and Kosaki, G., Primary structure of human carcinoembryonic antigen (CEA) deduced from cDNA sequence. Biochem. biophys. Res. Commun., 142, 511-518 (1987).

Pèlegrin, A., Terskikh, A., Hayoz, D., Chalandon, Y., Olsson, N.-O., Folli, S., BUCHEGger, F., KROMER, B., SchwarZ, K., MartiN, M., Martin, F. and MACH, J.-P., Human carcinoembryonic antigen cDNA expressed in rat carcinoma cells can function as a target antigen for tumor localization of antibodies in nude rats and as rejection antigen in syngeneic rats. Int. J. Cancer, 52, 110-119 (1992).

Ponte, P., NG, S.-Y., Engel, J., Gunning, P. and Kedes, L., Evolutionary conservation in the untranslated regions of actin mRNAs: DNA sequence of a human beta-actin cDNA. Nucl. Acids Res., 12 , 1687-1696 (1984)

RoOney, B.C., Horne, C.H.W. and Hardman, N., Molecular cloning of a cDNA for human pregnancy-specific $\beta 1$-glycoprotein: homology with human carcinoembryonic antigen and related proteins. Gene, 71, 439-449 (1988).

SAKURAGI, N., Serum SP1 and hCG beta sub-unit (hCG beta) levels in choriocarcinoma, invasive mole, and hydatidiform mole: clinical significance of SP1/hCG beta ratio. Gynecol. Oncol., 13, 393-398 (1982).

SAMBroOK, J.E., Fritsch, J, and Maniatis, T., Molecular cloning: $a$ laboratory manual (2nd ed.), Cold Spring Harbor Laboratory, New York (1989).

SHIVELY, J.E. and BEATTY, J.D., CEA-related antigens: molecular biology and clinical significance. CRC Crit. Rev. Oncol. Hematol., 2, 355-399 (1985)

Thompson, J.A., Grunert, F. and Zimmermann, W., The carcinoembryonic-antigen-gene family: molecular biology and clinical perspectives. J. clin. Lab. Analysis, 5, 344-366 (1991). 